\title{
OBITUARY
}

\section{MARIYA ARONOVNA BALTER}

Mariya Aronovna Balter, a well-known production scientist, specialist in the area of metallurgy and heat treatment, and Candidate in Technical Sciences, died on May 14, 1987, at the age of 70 after a short and serious ilness.

After graduation in 1939 from Kharkov Polytechnic Institute, M. A. Balter worked continously for 48 years in leading transportation machinery plants, traveling the path from forewoman of a heat treat shop (in the years of the Great Patriotic War) to assist head of a section of the central laboratory of a large production union. She worked for about 30 years in this job, combining practical and organizational activity with major scientific-research work.

M. A. Baiter was a person of principle and able to correctly evaluate the reliability of investigation results and the possibility of their practical use in large-scale production. A many-sided erudite specialist, in the post-war period $M$. A. Balter directiy participated in the development of diesel locomotives, diesel engines, and other complex technology.

1. A. Balter published more than 130 published worls, including three fundamental monographs, and received 10 inventor' certificates. Mariya Aronovna devoted much attention to the study of fatigue and brittle failure. In her last monograph, "Fractography - a Means of Diagnosing Failed.Parts," published in 1987, her rich experience as a production worker and scientist was concentrated. For her investigations 1 . A. Balter was four times awarded that D. K. Chernov and N. A. Minkevich prizes and more than once awarded medals of the Exhibition of Accomplishments of the National Economy of the USSR. She was deservedly awarded the Order of the Workers Red Banner and other government honors.

M. A. Balter generously devoted her attention and experience to her young co-workers, skillfully directing their creative work. A number of candidate's theses were presented under her direction.

A member of the Communist Party of the Soviet Union since 1942, M. A. Balter actively participated in public life and devoted much attention to lecturing and propaganda work.

The kindest memory of Mariya Aronovna Balter, a fine person and an important specialist, is to forever preserve everything that she knew. 